\title{
An experiment for regulatory policy on broadband speed advertising
}

\author{
Shane Timmons ${ }^{1 *}$, Terence J. McElvaney ${ }^{1,2}$, Peter D. Lunn ${ }^{1,3}$
}

\begin{abstract}
Identifying whether hyperbolic advertising claims influence consumers is important for consumer protection, but differentiating mere "puffery" from misleading advertising is not straightforward. We conducted a pre-registered, online experiment $(N=367)$ to determine whether pseudo-technical advertising claims about broadband speed bias consumer choice. We tested whether these claims lead consumers to (i) make suboptimal choices and (ii) choose faster, more expensive broadband packages than they otherwise would. We also tested a potential policy response, consisting of consumer information on broadband speeds and how they are advertised. One-in-five consumers chose a provider advertising "lightning fast" broadband over another offering the same speed at a cheaper price. Both pseudo-technical claims and standard puffery (e.g. "Best Deal!") led consumers seeking fast broadband to choose faster, more expensive packages than consumers who saw no such claims. The information intervention (i) decreased the proportion of suboptimal decisions, (ii) increased the likelihood that consumers switched package, and (iii) improved understanding of speed descriptions. The findings do not support tough regulation on product descriptions; alternative softer interventions may be more beneficial. The study also demonstrates how applied behavioural economics can provide bespoke evidence for regulatory policy.
\end{abstract}

JEL Classification: D12; D18; D83; D90; M37; M38

Keywords

decision-making - behavioural economics - consumer protection - telecommunications

${ }^{1}$ Economic and Social Research Institute (ESRI), Dublin

${ }^{2}$ Queen Mary University of London

${ }^{3}$ Department of Economics, Trinity College Dublin

${ }^{*}$ Corresponding author: shane.timmons@esri.ie

\section{Introduction}

Consumer policy typically distinguishes between marketing practices that mislead and those that harmlessly exaggerate to capture attention. For instance, the United States Federal Trade Commission "generally will not pursue cases involving obviously exaggerated or puffing representations, i.e., those that the ordinary consumers do not take seriously" (FTC, 1984).

This concept of harmless "puffery" originated in common law back in Victorian times. However, it can be difficult to distinguish between puffery and claims that mislead consumers and hence cause harm. The present study demonstrates how applied behavioural economics can generate relevant empirical evidence for a regulator. The experimental study focused on the broadband market and was undertaken in collaboration with the Commission for Communications Regulation (ComReg) in Ireland.

Consider two consumers shopping for a broadband package. Jim knows little about broadband speeds but thinks the Lightning Fast, Next-Generation package for $€ 60$ per month must offer better service than the Superfast package at $€ 40$. By contrast, Rosie recognises that both packages offer maxi- mum speeds up to $100 \mathrm{Mbs}$, so she simply chooses the cheaper one. The primary aim of this study was to determine whether broadband consumers respond like Jim or like Rosie to such pseudo-technical claims. In other words, do consumers treat them as puffery or not?

The work was motivated by ComReg's concerns about how broadband speed is marketed. One possibility is that broadband customers may be particularly susceptible to puffery given the technical nature of the product. Successive technologies necessarily introduce consumers to new words and concepts ("superhighway", "Wi-Fi", "fibre"). This may make it easier to design effective yet empty marketing claims; to those in the know they look like puffery, but to the unwary they appear to be an attribute.

The experiment was conducted online and sought to reveal how the influence of pseudo-technical claims found in Ireland's broadband market compare with the effect of meaningful technical labels (speed in megabits per second; "Mbs") and marketing claims that clearly constitute puffery ("Best Deal", "Great Value"). In addition to this diagnostic test, the experiment tested a potential policy remedy. Decisions were recorded before and after reading information designed to 
improve understanding of broadband speed and how it is advertised.

Our findings suggest that a significant minority of consumers will pay more for a product advertised with an empty, pseudo-technical claim. One-in-five participants opted for broadband advertised as "TurboFast" or "NextGeneration" despite another provider offering the same speed at a lower price - they chose a dominated product. However, both pseudotechnical claims and standard marketing puffery had similar effects on consumers seeking fast broadband. Thus, given this general susceptibility to puffery, regulation of pseudotechnical language may impose a regulatory burden without alleviating the risk of consumer detriment. Importantly, following the information intervention, individuals who were initially susceptible to puffery became less likely to choose a dominated provider and more likely to choose cheaper broadband packages. More broadly, the results demonstrate how the methods of behavioural economics can be used to diagnose consumer policy problems and pre-test remedies.

\section{Background}

\section{Previous research}

Puffery is distinct from misleading advertising in two aspects: whether consumers believe claims and whether they factor them into choices (e.g. Cowley, 2006; Colaizzi, Crook, Wheeler \& Sachs, 2017). In the UK, puffery is defined as obvious exaggerations that "the average consumer... is unlikely to take literally"; in Australia, so exaggerated claims "that no one could possibly treat seriously or find misleading" (ASA, 2008; ACCC, 2019). These definitions arguably confound two empirical issues: whether consumers believe a claim and whether it influences their choices.

A reasonable consumer may take a hyperbolic claim seriously if it seems to convey technical information and the consumer lacks sufficient knowledge (e.g. Xu \& Wyer, 2000). Yet even where the claim is not believable, a reasonable person may act on it. People frequently make inferences beyond stated information and such inferences need not follow logically from premises. People often infer "pragmatic implications" when processing information, for example, inferring that the statement 'the absent-minded professor didn't have his car keys" implies that the professor lost or forgot his keys (Harris and Monaco, 1978, p. 3). Such pragmatic implications may be inferred from puffery. Consumers may assume that a highlighted attribute is unique or exceptional even if they do not take the associated claim literally, treating it as a signal of superiority over other products (Burke, Milberg \& Moe, 1997; Chakraborty \& Harbaugh, 2014). Thus, advertising a "TurboFast" broadband package may lead some consumers to infer that the product is faster than its competitors, even if they know the term to be technically meaningless.

Establishing whether claims are taken literally or influence choices can be difficult, particularly when the materiality of the influence is important for law (Richards and Preston, 1992). Surveys show that consumers can believe certain types of puffery and that it can impact product evaluations (Olshavsky \& Miller, 1972; Rotfield \& Rotzoll, 1980; Russo, Metcalf and Stephens, 1981; Simonson \& Holbrook, 1993; Toncor \& Fetscherin, 2012), but experimental research measuring the impact of puffery is rare.

\section{Experimental motivation}

Our aim was to design an experimental test to generate evidence for policy in two ways. First, we investigated whether pseudo-technical claims affect broadband choices by testing willingness to pay more for an equivalent speed when the expensive option carried a pseudo-technical claim ("Lightning Fast", "Next Generation"). The actual speed was specified, so no valid inference could be made that the product carrying the claim was in fact faster. In addition, because products with more attributes are more cognitively demanding to assess (e.g., Sela \& Berger, 2012), and uncertainty may increase the likelihood that consumers treat an empty claim as a signal of quality, the test also included bundled broadband products (e.g., with TV and phone included). Second, we compared willingness to choose a more expensive package when it was advertised with a pseudo-technical claim, with standard puffery, or with no puffery at all. This manipulation matters for evidence-based policy, since there is little point toughening the regulatory stance on pseudo-technical claims if standard puffery has the same effect.

Similarly, from an evidence-based policy perspective, in addition to diagnosing the impact of pseudo-technical claims, it is helpful to test remedies designed to improve decisions, perhaps especially those that impose minimal regulatory burden. A subsequent stage of the experiment therefore investigated whether a short information page could alleviate the risk of consumers being misled. Specifically, we tested two types of information: (1) information on which descriptions of broadband speed are meaningful and which are meaningless; (2) information on the speed requirements of different internet activities. The first was straightforwardly based on evidence that training can reduce susceptibility to misleading advertising (Harris, 1977; Gaeth and Heath, 1987), the second on evidence that product knowledge can protect consumers from being misled by puffery (Xu \& Wyer, 2004).

In summary, our research questions were:

(1a) Do pseudo-technical claims cause consumers to make objectively poor broadband choices?

(1b) Do pseudo-technical claims cause consumers to make more poor choices when evaluating bundled compared to standalone broadband products?

(2) Does the presence of pseudo-technical puffery increase the likelihood that consumers opt for faster more expensive broadband packages?

(3) Can any risks identified in questions (1) and (2) be alleviated through consumer advice? 


\section{Method}

The study was conducted in line with institutional policy for ethical conduct of research. Elements of the experiment, including participant exclusion criteria, were pre-registered (see Munafò et al., 2017). The pre-registration, including experimental code and data, is available at osf.io/9qmjn/.

\section{Participants}

Four-hundred consumers were recruited by a market research agency to be broadly representative of the adult population in Ireland. Of these, 32 indicated that they were not broadband consumers and 2 failed a quality control question. These participants were removed from all analyses, leaving a sample of 367 aged 18 to 70 years $(M=42.27, S D=13.43)$, comprised of 185 women and 182 men, 194 with a third-level degree and 211 in fulltime employment. Consistent with national estimates, the urban-rural split was 70:30. Participants received a link to the experiment on the online account with the agency. The payment for taking part was $€ 15$, but participants could opt to spend $€ 6$ of their payment in an unrelated experiment about online gambling competitions (99 participants did so, meaning they were paid $€ 9$ while the remaining participants received the full $€ 15$. Payments were deposited into the participant's panel account). Each participant was also entered at least once into a draw for one of ten $€ 100$ shopping vouchers.

\section{Design, materials and procedure}

The experiment was programmed and hosted on Gorilla (gorilla.sc; Anwyl-Irvine, Massonnié, Flitton, Kirkham \& Evershed, 2019). Materials were based on online offerings in the market, adhered to regulations and were approved by ComReg. To mimic how consumers make broadband decisions, participants undertook the experiment online (see Horton, Rand \& Zeckhauser, 2011). It proceeded over five stages matched to the research questions.

Stage 1:

(1a) Do pseudo-technical claims cause consumers to make objectively poor broadband choices?

(1b) Do pseudo-technical claims cause consumers to make more poor choices when evaluating bundled compared to standalone broadband products?

In Stage 1, there were four advertisements from fictional providers. To account for different internet-use requirements, the materials were designed such that two pairs offered low download speed (24Mbs) and two offered higher download speed (100Mbs). Within these pairings, the providers varied according to a 2 (claim: pseudo-technical, standard puffery) $\mathrm{x}$ 2 (bundling: bundled, unbundled) design, with the claim variable manipulated within-subjects and the bundling variable manipulated between (see Charness, Gneezy \& Kuhn, 2012). That is, within each pair, one was advertised with a pseudotechnical claim, the other with standard marketing puffery (Figure 1), and participants were randomly assigned to choose either standalone broadband $(n=193)$ or a broadband, TV and phone bundle $(n=174)$. Crucially, the pseudo-technical claim was always associated with a higher price than the standard one at that speed, such that the pseudo-technical provider was dominated. The four providers were randomised across conditions. Participants were informed that there were no right or wrong answers - we were interested simply in their preference. The task was to choose as they would in real life.

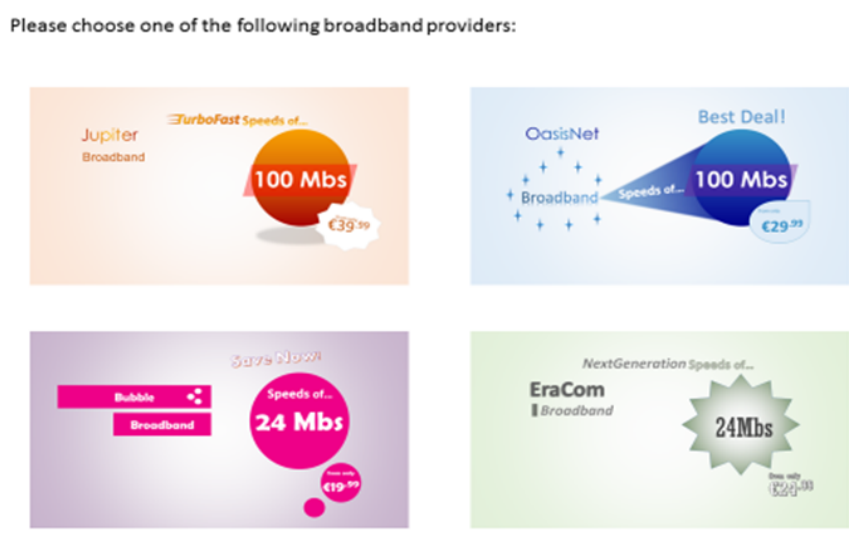

Figure 1. Example broadband provider choice screen in the unbundled condition.

Stage 2:

(2) Does the presence of pseudo-technical puffery increase the likelihood that consumers opt for faster more expensive broadband packages?

After participants chose a provider, Stage 2 presented four packages in ascending order of price and maximum download speed (Figure 2). There was one between-groups manipulation: participants were randomly assigned to see the fastest, most expensive package advertised with a pseudo-technical label $(n=130)$, a standard marketing label $(n=126)$ or no label $(n=111)$. Their task was again to choose as they would in real life.

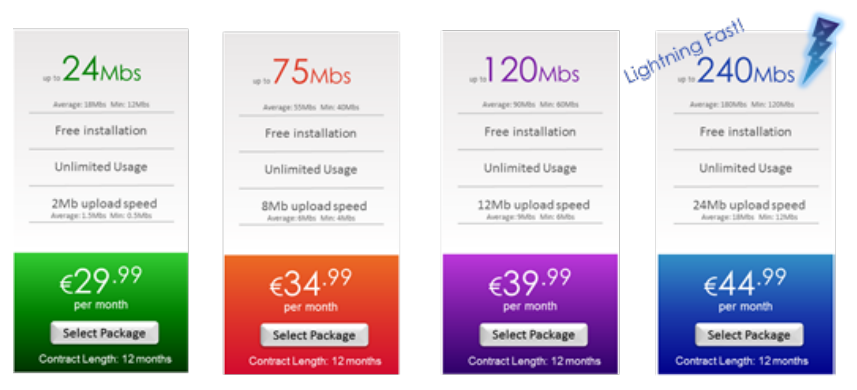

Figure 2. Example broadband packages for participants in the pseudo-technical condition.

Stages 3, 4 and 5:

(3) Can any risks identified in questions (1) and (2) be alleviated through consumer advice? 
In Stage 3, participants were randomly assigned to read one of three information pages: information that explained how broadband speeds are advertised (hereafter "Ads"; $n=$ 130 ), the same information plus a section on speed requirements of different internet activities ("Ads + Speed"; $n=113$ ) or information on the history of broadband ("Control"; $n=$ 124). Participants could not proceed past this stage until at least 30 seconds had elapsed (determined through pilot testing). Stages 4 and 5 repeated Stages 1 and 2 respectively. The providers and packages seen before and after the intervention were different and determined randomly. Each participant remained in the same between-groups condition (i.e., if they chose bundles in Stage 1, they chose bundles in Stage 4 too, and similarly for the label manipulation in Stages 2 and 5).

Following the experiment participants completed an unrelated experiment on premium rate services. The session concluded with questions about background characteristics and three multiple choice questions that probed understanding of broadband speed advertising. For example, one question asked:

Which of the following packages is most likely to offer the fastest speed?

- Superfast broadband

- Lightning Speed broadband

- Ultrafast broadband

- Next Generation broadband

These questions served as a manipulation check for the information stage. Participants in the Ads and Ads + Speed conditions should, for example, know that the correct answer is Ultrafast (300Mbs and above). We hypothesised that participants in the Ads and Ads + Speed conditions would perform better than those in the control condition.

\section{Results}

We consider each research question in turn as they correspond to each stage of the experiment. We report tests of pre-registered, directional hypotheses as one-tailed and all other tests as two-tailed.

(1a) Do pseudo-technical claims cause consumers to make objectively poor broadband choices?

In the first stage, $74 \%$ of participants opted for one of the two fast broadband providers, while the remaining $26 \%$ chose one of the cheaper but slower providers. A significant minority opted for a dominated product: $21 \%$ chose a provider advertised with a pseudo-technical claim rather than a cheaper alternative offering the same speed. A two-sample test of proportion indicated no difference between those who showed a preference for fast broadband and those who preferred slower broadband, $Z=1.13, p=.260$, two-tailed (Figure 3 ).

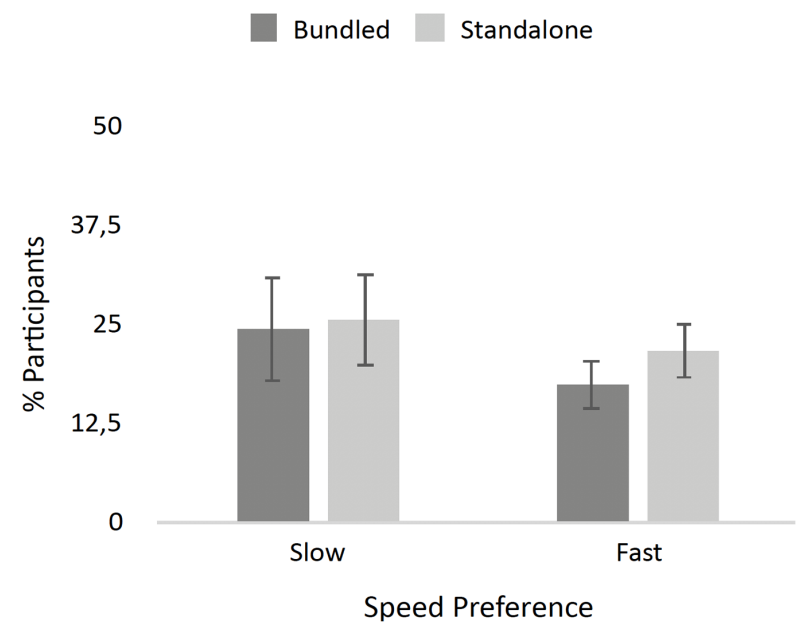

Figure 3. Percentage of participants choosing the dominated provider at each speed. Error bars are the standard error of the proportion.

(1b) Do pseudo-technical claims cause consumers to make more poor choices when evaluating bundled compared to standalone broadband products?

A two-sample test of proportion indicated no evidence that participants choosing bundled broadband were more likely to choose a dominated product than those choosing standalone broadband, $Z=0.90, p=.816$, one-tailed (Figure 3). Logistic regression models ${ }^{1}$ predicting choice of a dominated provider are reported in Table 1. The coefficients for having chosen a slow provider and seeing bundled broadband products in Model 1 confirm the above results and Model 2 shows that they hold when controls are added for being the bill-payer, gender, age, having a university degree, working fulltime and living in an urban area ${ }^{2}$.

(2) Does the presence of pseudo-technical puffery increase the likelihood that consumers opt for faster more expensive broadband packages?

The packages chosen in each condition in Stage 2 are presented in Figure 4. In Table 2, we report ordered logistic models with package choice as the dependent variable. As shown by the coefficients of the 'Label' variables in Model 3, participants were more likely to choose a faster package when the fastest one carried a standard marketing label than when there was no label present, $p=.021$, two-tailed, but there is no evidence that they were influenced by the pseudo-technical label, $p=.574$.

\footnotetext{
${ }^{1}$ The results are the same if multinomial models are run predicting choice of the four providers.

${ }^{2}$ We had planned to include a measure of the participant's current broadband speed, but $80 \%$ of the sample reported not knowing their own maximum broadband speed. Of the $20 \%$ who reported knowing, some gave implausible speeds (e.g. 15,000 Mbs) and so this data was not useable for analysis.
} 


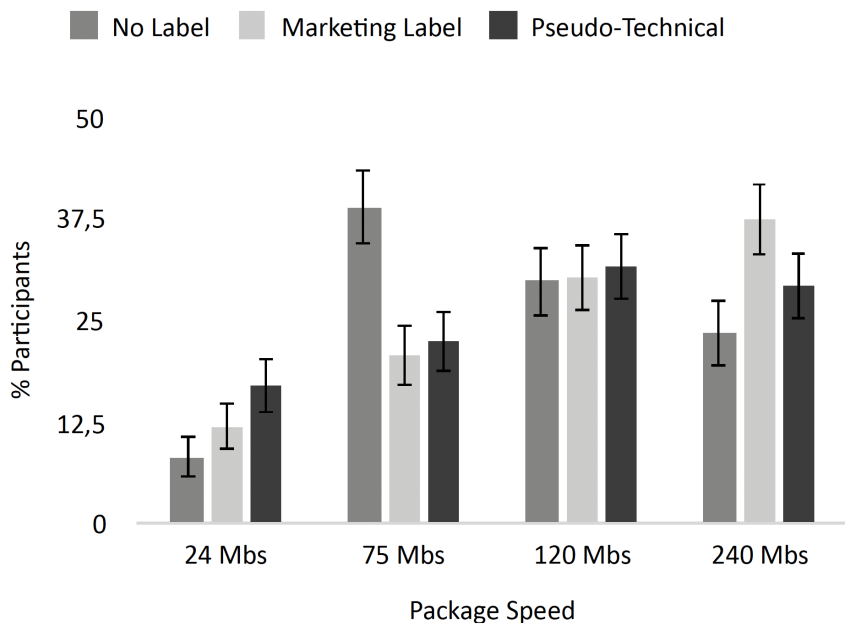

Figure 4. Broadband package speeds chosen by participants. Error bars are standard errors.

However, this model fails a Brant test of the proportional odds assumption. Generalised ordered logistic models reveal a similar qualitative pattern, but the failure of this assumption and the dispersion of the distributions in Figure 4 suggest that different participants may have responded to the labels in different ways. The multi-stage experimental design allows us to examine whether labels had different effects depending on the initial preference for more expensive, high-speed or for cheaper, low-speed broadband. Model 4 again presents an ordered logistic regression predicting package choice but includes also an interaction between the speed chosen in Stage 1 and the label in Stage 2. Although not initially hypothesised, the interaction between the Stage 1 choice and the pseudo-technical label is significant, $p=.002$, while the interaction with the standard label is also marginally significant, $p=.077$. Once these interactions are included in the specification the models pass the proportional odds test. The pattern of interactions suggests that, relative to the control group, the standard label increased the price and speed chosen by participants who opted for faster broadband in Stage 1, but had little impact on those who opted for slower broadband in Stage 1. By contrast, the pseudo-technical label had an impact in both directions: those who initially opted for faster broadband were pulled towards faster more expensive packages and those who initially opted for slower broadband were pulled towards slower cheaper ones. Tests for equality of coefficients on this interaction reveal no difference between the two label types for participants who opted for faster speeds in Stage $1, \chi^{2}(1, N=367)=1.82, p=.178$, two-tailed, but the pseudo-technical label had a significantly stronger repellent effect for participants who opted for slower speeds, $\chi^{2}(1, N=367)=4.65, p=.031$, two-tailed, as they were more likely to choose a slower, cheaper package. The results are the same when socio-demographic controls are added in Model 5. These also reveal that urban participants favoured faster packages.

\begin{tabular}{lcc}
\hline & $(1)$ & $(2)$ \\
\hline Bundled (Ref: Unbundled) & -0.22 & -0.18 \\
& $(0.26)$ & $(0.26)$ \\
Chose Slow (Ref: Fast) & 0.30 & 0.26 \\
& $(0.28)$ & $(0.29)$ \\
Bill-payer (Ref: Not) & -0.10 & \\
& & $(0.30)$ \\
Male (Ref: Female) & & -0.13 \\
& & $(0.27)$ \\
Over 40 (Ref: $\leqslant 40)$ & & 0.29 \\
& & $(0.28)$ \\
Degree (Ref: No Degree) & & -0.03 \\
& & $(0.27)$ \\
Fulltime (Ref: Not Fulltime) & & -0.31 \\
& & $(0.28)$ \\
Urban (Ref: Rural) & & -0.14 \\
& & $(0.28)$ \\
Constant & $-1.31 * * *$ & $-1.05 *$ \\
& $(0.19)$ & $(0.47)$ \\
\hline Obs. $\quad 367$ & 367 \\
\hline \multicolumn{2}{r}{ Note: ${ }^{\dagger} p<.10 ; * p<.05 ; * * p<.01 ; * * * p<.001$} &
\end{tabular}

Table 1. Logistic Regressions Predicting Choice of Dominated Providers in Stage 1

(3) Can any risks identified in questions (1) and (2) be alleviated through consumer advice?

In Stage 4, after reading the information, participants again chose a provider from four options. There was no evidence for a decrease in the number of participants choosing a dominated provider in any conditions, as evidenced from tests of the proportion of participants choosing the dominated provider before and after the information stage, within each condition: $Z_{\text {Control }}=0.78, p=.213$, one-tailed; $Z_{A d s}=0.79$, $p=.214$, one-tailed; $Z_{A d s+\text { Speed }}=0.86, p=.194$, one-tailed. Table 3 reports logistic regressions for choosing a dominated provider in Stage 4, controlling for whether the participant chose a dominated provider in Stage 1 and their speed preference. Model 6 shows no evidence for an effect of bundling or intervention, $p s>.662$. Participants with lower speed preferences (indicated by the 'Chose Slow' variable) were more likely to choose a dominated provider, $p=.007$, two-tailed, as were those who chose a dominated provider in Stage 1 ('Chose Dominated'), $p=.003$, two-tailed.

The information interventions were tailored to consumers who might be susceptible to pseudo-technical claims. Model 7 tests for an interaction between choosing a dominated provider in Stage 1 and the intervention. The main effect of 'Chose Dominated S1' shows that those who chose a dominated provider in Stage 1 were more likely to do so again, $p=.027$, two-tailed, but the interaction variable ('Intervention * Chose 


\begin{tabular}{|c|c|c|c|}
\hline & $(3)^{\dagger}$ & (4) & (5) \\
\hline \multicolumn{4}{|l|}{ Label (Ref: Control) } \\
\hline \multirow[t]{2}{*}{ Standard } & $0.49 *$ & $0.76^{* *}$ & $0.80 * *$ \\
\hline & $(0.23)$ & $(0.28)$ & $(0.28)$ \\
\hline \multirow[t]{2}{*}{ Pseudo-technical } & 0.13 & $0.47 *$ & $0.58 *$ \\
\hline & $(0.23)$ & $(0.27)$ & $(0.28)$ \\
\hline \multirow[t]{2}{*}{ Chose Slow S1 (Ref: Chose Fast) } & & $-1.19 * *$ & $-1.20 * *$ \\
\hline & & $(0.39)$ & $(0.39)$ \\
\hline \multicolumn{4}{|l|}{ Label * Chose Slow } \\
\hline \multirow[t]{2}{*}{ Standard - Chose Slow } & & $-0.97^{\dagger}$ & $-0.89^{\dagger}$ \\
\hline & & $(0.55)$ & $(0.55)$ \\
\hline \multirow[t]{2}{*}{ Pseudo-technical - Chose Slow } & & $-1.72 * *$ & $-1.72 * *$ \\
\hline & & $(0.55)$ & $(0.56)$ \\
\hline \multirow[t]{2}{*}{ Bill-payer (Ref: Not) } & & & -0.16 \\
\hline & & & $(0.23)$ \\
\hline \multirow[t]{2}{*}{ Male (Ref: Female) } & & & $-0.34^{\dagger}$ \\
\hline & & & $(0.20)$ \\
\hline \multirow[t]{2}{*}{ Over 40 (Ref: $\leqslant 40)$} & & & 0.17 \\
\hline & & & $(0.21)$ \\
\hline \multirow[t]{2}{*}{ Degree (Ref: No Degree) } & & & 0.01 \\
\hline & & & $(0.21)$ \\
\hline \multirow[t]{2}{*}{ Fulltime (Ref: Not Fulltime) } & & & 0.12 \\
\hline & & & $(0.21)$ \\
\hline \multirow[t]{2}{*}{ Urban (Ref: Rural) } & & & $0.55 * *$ \\
\hline & & & $(0.21)$ \\
\hline Obs. & 367 & 367 & 367 \\
\hline
\end{tabular}

Table 2. Ordered Logit Models of Package Choice in Stage 2

Dominated') shows that among this group the likelihood was lower for those in the Ads + Speed condition (13.04\%) than those in the control condition $(33.33 \%), p=.045$, one-tailed, and, as shown by a test of equality of coefficients, in the Ads condition $(37.04 \%), \chi^{2}(1, N=243)=4.75, p=.029$, two-tailed. The results are the same when socio-demographic controls are added (Model 8).

Importantly, participants in both advice conditions displayed a better understanding of how broadband speeds are advertised at the end of the experiment. A one-way ANOVA shows a strong overall effect of intervention read in Stage 3 on performance in the final multiple choice questions, $F(1,366)=$ $5.80, p=.003, d=0.37$. There was no difference between participants who read either of the interventions $\left(M_{A d s}=1.53\right.$, $\left.S D_{\text {Ads }}=0.97 ; M_{\text {Ads }+ \text { Speed }}=1.45, S D_{\text {Ads }+ \text { Speed }}=0.76\right), p=$ .483 , but both groups performed better than participants in the control groups $(M=1.19, S D=0.76)$, $p s<.001$, one-tailed.

When it came to choosing a broadband package for the

\begin{tabular}{|c|c|c|c|}
\hline & $(6)^{\ddagger}$ & $(7)$ & $(8)$ \\
\hline \multirow[t]{2}{*}{ Bundled (Ref: Unbundled) } & -0.19 & -0.24 & -0.24 \\
\hline & $(0.29)$ & $(0.29)$ & $(0.29)$ \\
\hline \multicolumn{4}{|l|}{ Intervention (Ref: Control) } \\
\hline \multirow[t]{2}{*}{ Ads } & -0.01 & -0.15 & -0.12 \\
\hline & $(0.34)$ & $(0.43)$ & $(0.44)$ \\
\hline \multirow[t]{2}{*}{ Ads + Speed } & -0.16 & 0.21 & 0.22 \\
\hline & $(0.36)$ & $(0.42)$ & $(0.42)$ \\
\hline \multirow[t]{2}{*}{ Chose Dominated S1 (Ref: Did Not) } & $0.91 * *$ & $1.13^{*}$ & $1.06^{*}$ \\
\hline & $(0.31)$ & $(0.51)$ & $(0.52)$ \\
\hline \multicolumn{4}{|l|}{ Intervention $*$ Chose Dominated } \\
\hline \multirow[t]{2}{*}{ Dominated - Ads } & & 0.42 & 0.55 \\
\hline & & $(0.72)$ & $(0.74)$ \\
\hline \multirow[t]{2}{*}{ Dominated - Ads + Speed } & & $-1.45^{*}$ & $-1.23^{\dagger}$ \\
\hline & & $(0.86)$ & $(0.87)$ \\
\hline \multirow[t]{2}{*}{ Chose Slow (Ref: Fast) } & $0.84 * *$ & $0.84 * *$ & $0.93 * *$ \\
\hline & $(0.21)$ & $(0.31)$ & $(0.32)$ \\
\hline \multirow[t]{2}{*}{ Bill-payer (Ref: Not) } & & & -0.25 \\
\hline & & & $(0.33)$ \\
\hline \multirow[t]{2}{*}{ Male (Ref: Female) } & & & 0.04 \\
\hline & & & $(0.30)$ \\
\hline \multirow[t]{2}{*}{ Over 40 (Ref: $\leqslant 40)$} & & & 0.19 \\
\hline & & & $(0.32)$ \\
\hline \multirow[t]{2}{*}{ Degree (Ref: No Degree) } & & & -0.13 \\
\hline & & & $(0.31)$ \\
\hline \multirow[t]{2}{*}{ Fulltime (Ref: Not Fulltime) } & & & 0.37 \\
\hline & & & $(0.33)$ \\
\hline \multirow[t]{2}{*}{ Urban (Ref: Rural) } & & & 0.29 \\
\hline & & & $(0.33)$ \\
\hline \multirow[t]{2}{*}{ Constant } & $-1.98 * * *$ & $-1.98 * *$ & $-2.31 * * *$ \\
\hline & $(0.34)$ & $(0.34)$ & $(0.61)$ \\
\hline Obs. & 367 & 367 & 367 \\
\hline
\end{tabular}

Table 3. Logistic Regressions Predicting Choice of Dominated Providers in Stage 4

second time, $19 \%(n=70)$ changed their choice from Stage 2. Two-sample tests of proportions show that more participants in the advice conditions (Ads: 21\%; Ads + Speed: 24\%) than in the control condition $(13 \%)$ changed their choice: $Z_{A d s}=1.67$, $p=.047$, one-tailed; $Z_{\text {Ads }+ \text { Speed }}=2.15, p=.016$, one-tailed. There was no difference between the two advice conditions: $Z=0.58, p=.559$, two-tailed.

More fine-grained analysis of whether there were systematic directional effects in changes of package is made problematic by small cell sizes, given the unexpected interaction between label and speed preference. The sample is small for assessing a three-way interaction between initial speed 


\begin{tabular}{lccccccc}
\hline & Whole sample & \multicolumn{2}{c}{ Control } & \multicolumn{2}{c}{ Ads } & \multicolumn{2}{c}{ Ads + Speed } \\
& Stage 2 & Stage 2 & Stage 5 & Stage 2 & Stage 5 & Stage 2 & Stage 5 \\
\hline Slow * Standard & $-.97^{\dagger}$ & .70 & .46 & $-2.64 * *$ & -1.28 & -.56 & .19 \\
& $(.55)$ & $(.92)$ & $(.92)$ & $(1.01)$ & $(.98)$ & $(1.03)$ & $(.98)$ \\
Slow * Pseudo-tech & $-1.72 * *$ & -.68 & -1.06 & $-2.24 *$ & $-1.94 *$ & $-3.73 * *$ & -.88 \\
& $(.52)$ & $(1.07)$ & $(1.08)$ & $(.91)$ & $(.90)$ & $(1.38)$ & $(.98)$ \\
\hline Obs. & 367 & \multicolumn{2}{c}{124} & & 130 & & 113 \\
\hline
\end{tabular}

Note: ${ }^{\dagger} p<.10 ; * p<.05 ; * * p<.01 ; * * * p<.001$.

Table 4. Interaction Models for Each Intervention, Predicting Package Choice in Stage 4

preference, label and intervention group. Furthermore, closer analysis revealed misfortune in the randomisation: the original interaction between speed preference and label in Stages 1 and 2 was significantly smaller in the control group. Given this, Table 4 presents separate models for each intervention group, showing the interactions between speed preference in Stage 1 and label for choices of package before (Stage 2) and after (Stage 5) the intervention. All interaction coefficients are reduced for the two advice groups (losing statistical significance in two cases) but not for the control group, consistent with the advice having reduced the impact of the labels. Given the sample and randomisation issues, however, this evidence should probably be regarded as suggestive but weak.

\section{Discussion}

The experiment showed that, prior to reading information about broadband speeds and how they are advertised, one-infive broadband consumers chose a provider advertised with a pseudo-technical claim over a cheaper provider offering the same speed. When choosing a package, pseudo-technical claims had a polarising effect on consumers: those looking for fast broadband chose a faster, more expensive package than they otherwise would have, whereas those wanting slow broadband chose a slower, cheaper one. Standard puffery affected only those consumers seeking fast broadband. The effect on consumers seeking fast broadband is perhaps more problematic from a consumer welfare perspective, since it leads to consumers paying more than they otherwise would. That this effect was observed for both pseudo-technical claims and standard puffery has policy implications. If pseudo-technical claims cause a sizeable minority of consumers to choose dominated providers, but when all else is equal they have the same effect as standard puffery, there may be little benefit of regulations limiting the use of pseudo-technical marketing of broadband speed without also imposing regulations on standard puffery.

More encouragingly, the experiment showed that informing consumers about broadband speeds and how they are advertised helped those consumers who were susceptible to pseudo-technical claims to avoid choosing a dominated provider. Moreover, consumers who read this information were also more likely to change their package choice. Al- though we are cautious about the directional analysis, the evidence is at least suggestive that the change mitigated the original effect of the label. Crucially, consumers who read the advice displayed better understanding of how broadband speeds are advertised relative to consumers who read the control information. The results therefore show a change in consumer choices through the use of a relatively soft intervention, especially among those originally susceptible to being misled.

The online experiment allowed systematic investigation of how pseudo-technical claims affect consumer choices, but some caveats are required. Although we designed our materials in collaboration with the national regulator and designed the stages to mimic real consumer choices, it could be argued that in real (as opposed to hypothetical) decisions consumers would be incentivised to be more careful in relation to unreliable marketing claims. However, the significant changes in choices among only those who read the information suggests that participants who initially chose the more expensive packages were engaged with the task, trying to make a good decision and learned from what they read. Moreover, other effects, such as urban participants seeking higher broadband speeds, are consistent with what we would expected to see in the market.

As well as providing evidence specific to pseudo-technical marketing of broadband speed, this study demonstrates how collaboration between researchers and policymakers can lead to more behaviourally informed policy-making. In this case, the evidence confirmed that there was a consumer protection issue, but arguably did not lend support to a tough regulatory line on permissible product descriptions, instead suggesting that softer, information-based interventions may suffice. The study therefore shows how applying the methods of behavioural economics to diagnose problems and pre-test remedies can make for more evidence-informed policy.

\section{Acknowledgments}

This work was undertaken as part of PRICE Lab, a research programme funded by the Competition and Consumer Protection Commission, the Commission for the Regulation of Utilities and the Commission for Communications Regulation. For helpful discussions, we thank Cameron Belton, Féidhlim 
McGowan, Deirdre Robertson, and the staff at the Commission for Communications Regulation.

\section{References}

ACCC (2019). Advertising and Selling Guide. Retrieved from www.accc.gov.au/publications/advertising-selling /advertising-and-selling-guide/avoid-misleading-or-de ceptive-claims-or-conduct/misleading-or-deceptive-con duct

Anwyl-Irvine, A. L., Massonnié, J., Flitton, A., Kirkham, N. \& Evershed, J. (2019). Gorilla in our midst: an online behavioral experiment builder. Behavior Research Methods.

ASA (2019). Misleading Advertising. Retrieved from www.

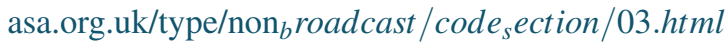

Burke, S. J., Milberg, S. J., \& Moe, W. W. (1997). Displaying common but previously neglected health claims on product labels: understanding competitive advantages, deception, and education. Journal of Public Policy \& Marketing, 16(2), 242-255.

Chakraborty, A., \& Harbaugh, R. (2014). Persuasive puffery. Marketing Science, 33(3), 382-400.

Charness, G., Gneezy, U., \& Kuhn, M. A. (2012). Experimental methods: Between-subject and within-subject design. Journal of Economic Behavior \& Organization, 81(1), 1-8.

Colaizzi, R., Crook, C., Wheeler, C., \& Sachs, T. (2017). The best explanation and update on puffery you will ever read. Antitrust, 31(3), 86-90.

Cowley, E. (2006). Processing exaggerated advertising claims. Journal of Business Research, 59(6), 728-734.

FTC (1984). Policy Statement on Deception. Appended to Cliffdale Associates, Inc., 103 FTC. 110, 174 (1984).

Gaeth, G. J., \& Heath, T. B. (1987). The cognitive processing of misleading advertising in young and old adults: Assessment and training. Journal of Consumer Research, 14(1), 43-54.

Harris, R. J. (1977). Comprehension of pragmatic implications in advertising. Journal of Applied Psychology, $62(5), 603$.

Harris, R. J., \& Monaco, G. E. (1978). Psychology of pragmatic implication: Information processing between the lines. Journal of Experimental Psychology: General, 107(1), 1-22.

Horton, J. J., Rand, D. G., \& Zeckhauser, R. J. (2011). The online laboratory: Conducting experiments in a real labor market. Experimental economics, 14(3), 399-425.
Munafò, M. R., Nosek, B. A., Bishop, D. V., Button, K. S., Chambers, C. D., Du Sert, N. P., et al. (2017). A manifesto for reproducible science. Nature Human Behaviour, 1(1), 0021.

Olshavsky, R. W., \& Miller, J. A. (1972). Consumer expectations, product performance, and perceived product quality. Journal of Marketing Research, 9(1), 19-21.

Richards, J. I., \& Preston, I. L. (1992). Proving and disproving materiality of deceptive advertising claims. Journal of Public Policy \& Marketing, 11(2), 45-56.

Rotfeld, H. J., \& Rotzoll, K. B. (1980). Is advertising puffery believed?. Journal of Advertising, 9(3), 16-45.

Russo, J. E., Metcalf, B. L., \& Stephens, D. (1981). Identifying misleading advertising. Journal of consumer research, 8(2), 119-131.

Sela, A., \& Berger, J. (2012). How attribute quantity influences option choice. Journal of Marketing Research, 49(6), 942-953.

Simonson, A., \& Holbrook, M. B. (1993). Permissible puffery versus actionable warranty in advertising and salestalk: an empirical investigation. Journal of Public Policy \& Marketing, 12(2), 216-233.

Toncar, M., \& Fetscherin, M. (2012). A study of visual puffery in fragrance advertising: Is the message sent stronger than the actual scent?. European Journal of marketing, 46(1/2), 52-72.

Xu, A. J., \& Wyer Jr, R. S. (2010). Puffery in advertisements: The effects of media context, communication norms, and consumer knowledge. Journal of Consumer Research, 37(2), 329-343. 